\title{
How do contract types and incentives influence driver behavior?-An analysis of the Kigali bus network
}

\author{
Leif Sörensen ${ }^{1,2,3}$ \& Jan Schlüter (iD 1,2,4,5凶
}

The rapidly growing city of Kigali has a bus network that is undergoing increased development as underlined in its Transport Master Plan. Two schemes of bus driver remuneration coexist in the city: One constitutes a hybrid salary and commission system, while the other pays a fixed monthly salary. This paper examines the effect of these differing compensation schemes on driver behavior in Kigali using survey data from 2019. The analysis applies linear models incorporating various aspects of driver behavior in a principal-agent framework. The results indicate that the performance-based compensation scheme is associated with higher per-trip passenger fluctuation and faster driving (possibly due to drivers aiming to accrue a higher income) compared to the fixed-wage system. Policy implications comprise the inclusion of further criteria in incentive contracts to internalize potential negative externalities on society, e.g., to hinder the endangerment of passenger safety by appropriately incentivizing drivers. In conclusion, bus drivers who are compensated by performance are more likely to alter their behavior, responding to the incentive scheme through several channels.

\footnotetext{
${ }^{1}$ Flexible Transport Systems and Complex Urban Dynamics Research Group, "Friedrich List" Faculty of Transport and Traffic Sciences, Technical University of Dresden, Hettnerstr. 1, 01069 Dresden, Germany. ${ }^{2}$ Econophysics Lab, Chair for Network Dynamics, Center for Advancing Electronics Dresden (cfaed), Technical University of Dresden, Helmholtzstr. 18, 01069 Dresden, Germany. ${ }^{3}$ Thinktank of Aeronautics, Aerodynamics and Aerospace Technology, Marschblick 5, 25866 Mildstedt, Germany. ${ }^{4}$ Institute for the Dynamics of Complex Systems, Faculty of Physics, Georg-August-University of Göttingen, Friedrich-Hund-Platz 1, 37077 Göttingen, Germany. ${ }^{5}$ Next Generation Mobility Group, Department of Dynamics of Complex Fluids, Max-Planck-Institute for Dynamics and Self-Organization, Am Fassberg 17, 37077 Göttingen, Germany. ${ }^{凶}$ email: jan@schluetergroup.org
} 


\section{Introduction}

he nature of passenger mobility is changing rapidly. Annual passenger traffic in the world is projected to exceed 80 trillion passenger kilometers by 2030, a fifty percent increase from 2015 figures [ITF 2017]. Despite this trend, transport infrastructure in the developing world has been slow to adjust to the rising demand, with Sub-Saharan Africa being a prime example. Low-income countries in this region have an average road density that is less than one-third of the density in other low-income countries [Ali et al., 2015]. Although the annual urban growth rate in Sub-Saharan Africa is the highest worldwide at 4 percent, inadequate planning and degrading transport infrastructure remain defining characteristics of this region [Sietchiping et al., 2012]. Due to the rapid urban transformation of Africa, improving urban accessibility and mobility is critical for inclusive and sustainable urban development. However, issues including poor traffic management and governance of public transport systems continue to contribute negatively to livability, and accessibility varies highly by income [Bryceson et al., 2003].

Consequently, the World Bank has been constantly increasing its urban transport commitments, allocating more than half of its total transport lending to improving the road infrastructure, with an additional emphasis on governance issues [World Bank, 2014]. Recommended policy measures include the provision of adequate human resources, enhanced civil society participation, increased involvement of the private sector, car fleet regulation, and the provision of "an integrated and hierarchical public transport system that is efficient, reliable, and capable of serving the needs of constantly evolving populations and the urban economy", to name a few [Stucki, 2015, p. 68]. Notwithstanding, there have been mixed results regarding the effectiveness of transport policies that aim at improving the current state of public transport in developing countries, e.g., see Boateng (2021) for the case of road safety in Ghana or Schalekamp and Behrens (2010) for the case of paratransit formalization in South Africa. While these results point towards the relevance of adequate transport policy, this paper does not assess the effectiveness of the respective interventions.

Despite the rapid population growth in Sub-Saharan Africa, the modal share of buses has been declining [Tembe et al., 2019]. This can be partly attributed to the inability of transport providers to respond to current passenger needs, as well as accelerating motorization in major cities [Iles, 2005]. For example, in the Rwandan capital, Kigali buses are only the third most utilized vehicular mode of transport, following motorcycles and cars. Walking is the most popular mode of transport when traveling to school or to the workplace [City of Kigali, 2019]. As shown by Obeng-Odoom for the Ghanaian context, a sharp increase of motorized individual transport, i.e., mainly car traffic, encompasses several negative externalities for society [Obeng-Odoom, 2010]. For this reason, the Rwandan municipal authorities aim to reverse this trend by improving the public bus network with the objective of finding a sustainable mode of mass public transport [Allaire et al., 2019]. For example, efficient public bus transport may allow to cut transport-related emissions in the context of a growing city [Colenbrander et al., 2019].

Therefore, this paper investigates public bus transport rather than the more popular but informal and unsafe alternative mobility services. While empirical studies in developing and developed countries alike have demonstrated the inverse relationship between car ownership and the demand for local buses, local factors such as traffic congestion, service reliability, and policies also play a role in this regard [Tembe et al., 2019;
Kutzbach, 2009, Santoso et al., 2012; Obeng-Odoom, 2010]. Kigali's bus routes are divided into four zones, serviced by three private companies that operate without any government subsidy. KBS (Kigali Bus Services) was awarded Zone 1, Royal Express Limited was awarded Zone 2, and RFTC (Rwanda Federation of Transport Cooperatives) was awarded Zones 3 and 4 as a result of a tender in 2013. Importantly, Royal Express and KBS compensate their drivers with a fixed wage, while RFTC drivers work on a hybrid salary and commission system. As bus driver behavior plays a role in determining the quality of transport services, it has implications for variables such as efficiency, passenger safety, and revenues from service provision, among others [see Gwilliam, 2003; Pucher et al., 2005, also Htun et al., 2012].

Thus, this paper aims to study the effect of varying compensation schemes on bus driver behavior in Kigali, Rwanda. We seek to achieve this objective by performing statistical analysis with ordinary least squares and logistic regression utilizing survey data for the bus network of Kigali. It contributes to the existing literature by providing empirical grounds to assess external validity concerns in previous studies on driver behavior and labor supply in a developing country context. Among other variables, the dataset consists of information about trips, stops, passenger numbers, revenues, and bus operators. Bus operators have (in part) different compensation schemes for their drivers, which makes it possible to ascertain the corresponding remuneration system only by knowing which company services a given route in the city.

Kigali was chosen for the analysis as it has been the epicenter of the rapid population growth and socioeconomic change in post-genocide Rwanda. The demographic boom can be largely attributed to internal migration, the return of refugees from neighboring countries, and natural growth [Baffoe et al., 2020]. In 2000 and again in 2005, the official boundaries of the city were increased from an initial $314 \mathrm{~km}^{2}$ to $730 \mathrm{~km}^{2}$, aiming to accommodate the growing population. However, the newly added rural and agricultural areas lacked urban services and infrastructure [Twarabamenye and Mukashema, 2012]. Kigali continues to experience an average annual population growth rate of 4 percent, one of the highest in Africa, and its population is expected to reach 4 million by 2040 [REMA, 2013, NISR, 2012]. In turn, these dynamics have led to spatial expansion and the rise of informal settlements, which account for two-thirds of the increase in city size and approximately $79 \%$ of the urban population [NISR, 2012]. This acceleration of demographic and spatial growth increases the importance of Kigali's public transport. Coordinated and accessible public transport can serve to avoid traffic congestion in rapidly growing cities, improve road safety, and bridge gaps between different socioeconomic segments of the population [Aljoufie et al., 2013]. In light of these dynamics, it is critical to better understand what may influence the behavior of bus drivers, as their actions impact the quality of public transport services in any urban environment. Public transport quality, in return, affects its usage and is therefore of increased importance in light of population growth and urbanization.

The rest of this paper is organized as follows: section "Theoretical Framework and State of Research" gives a brief review summarizing the current state of the literature and describes the theoretical framework. Section "Empirical approach" presents the estimation strategy in detail and provides reasoning for the empirical methodology. Section "Results" summarizes the results, while section "Discussion" discusses the findings and outlines some caveats. Section "Conclusion" concludes. 


\section{Theoretical framework and state of research}

Since bus driver behavior is a relevant factor for public transport quality and road safety, a precise understanding thereof is essential to improve service and, in return, increase ridership in the future. The following section provides the state of the literature on payment schemes or contract types on employee behavior and the underlying theoretical concepts.

Fixed wages and performance-based contracts have been the subject of extensive discussion in economic literature. The aim of incentive contracts is to improve worker effort and thus lower firm costs [Lazear, 1986]. The use of incentive contracts to align the employees' interests with that of the employer has been extensively documented in agricultural economics, with sharecropping being a classic case of an output-based compensation arrangement [Johnson, 1950, Stiglitz, 1974]. It has been highlighted that the downsides of performance-based contracts include higher uncertainty on part of the employee, which induces demand for a higher fixed component of the wage [Weitzman, 1980]. On the other hand, a fixed wage contract places all risk on part of the employer.

The empirical evidence for the effectiveness of performance(based) pay in improving actual performance is mixed [Weibel et al., 2009]. The motivation crowding-out effect suggests that external monetary incentivization may have a negative impact on productivity [Titmuss, 1998]. These hidden costs arise when an intrinsically motivated worker views an action as externally driven instead of internally appealing as a result of performance pay. In turn, this can lower worker productivity through impaired selfdetermination (because workers are "forced" to behave in a certain manner due to the intervention) and impaired self-esteem (when workers have the impression that their intrinsic motivation is not recognized) [Frey and Oberholzer-Gee, 1997, Frey and Jegen, 2001, Gneezy and Rustichini, 2000]. Other empirical studies claim to have established a positive relationship between performance pay and actual performance [Prendergast, 1999, Lazear, 2000]. This conclusion would imply a positive wage elasticity of labor supply. However, contrary examples such as the negative association between hourly labor supply and transitory wage changes for inexperienced cab drivers in New York City demonstrate that the existence of a daily income target and the day-by-day nature of labor decisions can counteract positive wage elasticity [see Camerer et al., 1997, also Fehr and Goette, 2007]. Thus, the evidence regarding the effectiveness of incentive contracts (relative to fixed-wage contracts) does not allow for a general statement in favor of one compensation scheme over the other.

However, several conditions for the effective functioning of performance-based pay have been identified, including delegation of responsibility, fair assessment of employee effort, motivation, and other behavioral elements [Daido, 2007; Weibel et al., 2009; Wakabayashi, 2019]. Examples show that transitioning from a salary to a fee-for-service scheme affects the clinical behavior of physicians, resulting in better continuity of care and more patient visits, but less patient satisfaction [Gosden et al., 2000; Brekke et al., 2020]. In Vietnam and Hawaii, empirical studies on fisheries demonstrate that share contracting improves economic performance [Nguyen and Leung, 2009; Pham et al., 2013]. Performance pay was found to have reduced corruption in the Korean public service [Kwon, 2014], while Palmrose (1989) finds that auditors' work hours are unaffected by contract type. Workers may also respond to performance pay by reducing the quality of their output [Paarsch and Shearer, 2001], or reduce willingness to participate in unpaid activities [Jones, 2013]. Further, performance pay may increase egoism and less employee cooperation [Burks et al., 2009].
For the transport sector, the influence of remuneration schemes on driver behavior has been studied before with research areas ranging from safety to efficiency. Htun et al. (2012) discuss how different types of salary systems induce divergent drivers' behavior and argue that a fixed salary system creates the weakest incentives for bus driver effort. However, a fixed salary may better conserve the vehicle and contributes to the safety and reliability of bus services due to more considerate and slower driving. Thus, a hybrid salary and incentives system (such as the one employed by RFTC) may solve some of the problems associated with the fixed salary system. However, a monitoring arrangement is required to ensure that indicators relevant to the incentive scheme are appropriately measured. Failure to do so may lead to drivers supplementing their incomes by not turning in the full revenue collected [Gwilliam, 2003].

Importantly, incentive contracts must be tailored to the possibility that drivers may not exclusively pursue profit-maximizing behavior and may have reference-dependent preferences [Schlüter et al., 2020]. A study comparing two compensation schemes for bus drivers in Santiago de Chile found that those with a performance-based contract altered their behavior to compete for passengers. Specifically, per-passenger compensation leads to less bunching of buses, lowering the waiting time for passengers, but it also leads to more accidents and less passenger comfort due to aggressive driving to obtain more passengers. Thus, drivers engage in a strategic game to maximize their profits [Johnson et al., 2015]. An examination of minibus competition in Hong Kong was largely consistent with the findings from Chile, showing that drivers who had performance-based incentive contracts exhibited higher accident rates and lower peak-period journey times compared to those that were paid a fixed wage [Rusco and Walls, 2001]. Importantly, the existence of one type of contract does not necessarily exclude the other, as their simultaneous use can be an efficient mechanism to induce the socially optimal behavior of drivers [Rusco and Walls, 2004].

For the wider Sub-Saharan African context, Boateng (2020) points to political economy factors as explanations for minibus driver behavior in Ghana. The study highlights issues such as high competition, job insecurity, and low wages as mechanisms through which undesirable driving practices such as overspeeding are induced. In Tanzania, speeding and unsafe driving practices are pathways through which drivers exert their agency due to an abundance of competition and a lack of negotiating power vis-àvis their employers [Rizzo, 2011]. Further evidence from Ghana suggests that while remuneration schemes are an important determinant of driver behavior, bus drivers often resort to danger-prone driving to meet their revenue targets [Boateng, 2021]. Further findings from Ghana demonstrate that aggressive competition among drivers is common, which is often reflected by a multitude of factors such as a lack of proper vehicle maintenance and speeding [Dotse et al., 2019]. A study from Kenya explicitly points to incentive-based compensation schemes as the root cause of poor service quality in public transport, with many local cooperatives switching to fixed salaries to address this issue [Behrens et al., 2017]. The results of these studies highlight the importance of recognizing road safety issues as a critical aspect of agents' utility-maximizing behavior.

As indicated above, the underlying theoretical concept is agency theory in social sciences, also known as the principal-agent problem [Jensen and Meckling, 1976]. The principal-agent problem arises when an agent (e.g., worker, employee) with priorities diverging from those of the principal (e.g., firm, organization, employer) has the capacity to make decisions on behalf of the latter. This scenario is characterized by hidden action, with the agent's actions not being (directly) observable for the principal. 
In the general economic environment, the principal is riskneutral, and he/she derives utility solely from profits. The level of effort exerted by the agent is defined as $e \in \mathrm{E}$. Profits $(\pi)$ constitute a continuous random variable with domain $(a, b)$ and the distribution being conditional on the effort of the agent with $F(e)$. The associated density $f(e)$ is positive for all $e \in E$ and $\pi \in[a, b]$. The utility of the agent is defined by the Bernoulli utility function

$$
u(w, e)=m(w)-l(e),
$$

where $w$ expresses compensation. Moreover, $\mathrm{m}^{\prime}>0, m^{\prime \prime}<0$, and $l^{\prime}>0$. Lastly, the agent has a reservation utility of $\underline{u}=c$. As the principal cannot directly observe the agent's effort $e$, he/she is obliged to offer a compensation scheme of the type $w(\pi)$. Consequently, the agent's problem (if the contract is accepted) can be summarized as

$$
u(w, e)=m(w)-l(e) s . t . \underline{u}=c .
$$

After the agent's choice of effort produces profits, he/she is paid according to $w(\pi)$. As the principal's sole concern is the profit, his/her goal is to devise $w(\pi)$ such that expected profits are maximized. During this process, the principal must consider whether the agent will accept the contract given $u$ and what effort the latter will exert given $w(\pi)$, i.e., $e(w(\pi))$.

In Kigali, bus providers compete for drivers. Under the assumption of perfect information and rationality, drivers analyze whether their expected utility of any job $(u)$ outweigh their reservation utility $(u)$. The driver chooses the employment opportunity that maximizes his/her utility. This can be expressed as follows:

$$
u\left(w_{i}, e_{i}\right)=m\left(w_{i}\right)-l\left(e_{i}\right) \text { s.t. } \underline{u}=c \forall i=1, \ldots, n,
$$

where $n$ denotes the number of employment opportunities for the driver. In the expanded model, wages and effort are uniquely determined for each job, as $w(\pi)$ and $e(w(\pi))$ are potentially different for each position. The measurement and modeling of $e$ in this paper are discussed in section 3.

While incentive contracts have seen widespread usage in order to address the principal-agent problem [Ghatak and Pandey, 2000; Poblete and Spulber, 2012], the design of optimal contract terms may remedy incentive asymmetries [Olynk and Wolf, 2010]. Ideally, the agent will exert a level of effort that maximizes utility and profit simultaneously. Salaries that are based solely on performance impose a risk on the agent to not receive a wage if he/she fails to generate any profit. Adding a fixed component to the incentive contract shares the risk between agent and principal. In the case of fixed-wage contracts, $w$ is a constant that ceases to depend on the principal's profit. Consequently, the agent does not have any incentive to exert effort, which inhibits the profitmaximization of the principal.

Moreover, agency theory seeks to address the moral hazard issue through monitoring of the agent [Hart and Holmström, 1987]. Monitoring solves the issue of asymmetric information for the principal [Strausz, 1997]. As the agent's actions become observable for the principal, the latter can act to ensure that the former exerts the degree of effort that maximizes the profit of the firm. However, the delegation of monitoring to a supervisor can create a new principal-agent problem between the principal and the supervisor if the latter collided with the agent [Tirole, 1986].

Agency costs occur for the principal through monitoring, as well as for the agent in form of bonding costs to demonstrate his/ her effort to the principal [Jensen and Meckling, 1976]. Hence, the principal must consider the tradeoff between agency costs and improved agent performance when deciding whether to offer an incentive contract or a fixed-wage contract [Conlon and Parks, 1990]. In Kigali, KBS and Royal Express opted for a salary system that pays drivers a fixed wage regardless of performance. If the conditions above hold, the choice of RFTC to compensate its drivers with a hybrid salary and commission system would thus necessitate that this scheme improves driver performance to the degree that it makes the associated agency costs worthwhile for the company. The basic paradigms of agency theory assume an absence of private information for the principal, the existence of benevolent judicial systems that enforce the contract, the ability of the principal and the agent to commit to the contract, and their complete rationality [Laffont and Martimort, 2009].

Notwithstanding, some assumptions of agency theory are not directly transferable to a real-world setting. Although operators lack real-time monitoring equipment, independent studies commissioned by the Kigali government such as the Interim Transport Master Plan Report of 2019 provide valuable information for the principals [City of Kigali, 2019]. Hence, companies have some degree of private information about the general transport environment in the city. A UNDP report from 2013 suggests imperfect enforceability for required jurisdiction in Rwanda [Maveneka and Ruramira, 2013]. Both drivers and operators could stand to benefit: Drivers can factor in the constrained effectiveness of legal action undertaken by their employers, while companies can sanction drivers in case of non-compliance with their contracts with limited fear of prompt legal repercussions if any. Repeated studies have discussed and demonstrated that not all actors are fully rational utility-maximizers in a real-world setting [see Simon, 1955, Kahneman and Tversky, 1979]. While the survey data is insufficient for the construction of a bounded rationality model of driver behavior, findings of similar studies will be utilized in the results section.

In agency theory, it is further assumed that more monitoring will increase work effort, called the "disciplining effect". However, if the principal and the agent share a personal relationship with reduced social distance, monitoring may be interpreted as a sign of distrust by the agent, leading the latter to exert less effort (called the "crowding-out effect") [Frey, 1993]. If the relationship is distanced, the disciplining effect will dominate the crowdingout effect [Dickinson and Villeval, 2008]. This is unlikely to be of concern in Kigali: Each company employs a number of drivers that are active in a competitive market. Hence, there is a negligible likelihood that close, personal relationships between drivers and their companies will induce the crowding-out of driver effort due to monitoring.

However, changes in productivity may not only relate to incentive effects but may result from sorting, i.e., the capacity of a performance pay scheme to attract workers that exhibit a differential level of effort [Lazear, 2000, Eriksson and Villeval, 2008]. The sorting effect can be multidimensional, with factors besides productivity also playing a role [Dohmen and Falk, 2011]. This paper does not empirically distinguish the incentive effect and the sorting effect.

Lastly, this work includes average vehicle speeds as a proxy to measure the aggressiveness of driving behavior. The authors seek to ascertain whether the results of a similar study from Santiago de Chile by Johnson et al. (2015) generalize to the Rwandan context, i.e., if performance-based pay encourages faster driving on average, potentially leading to an increased accident rate.

\section{Empirical approach}

The following section illustrates the empirical framework of this paper and seeks to rationalize the decisions on model specification and methodology. Since the data does not contain detailed information about drivers' control variables, such as age, driving experience, and perception of penalties [Jørgensen and Polak, 1993], the paper follows the empirical approach by Johnson et al. (2015). The coexistence of both compensation schemes in Kigali 
allows for a comparison between trips that are run by RFTC (which compensates its drivers based on a hybrid salary and commission system) and by KBS and Royal Express.

In this paper, $e$ is modeled through the average per-trip occupancy rate and its standard deviation, as well as bus hours on a given day. Any measures derived from the occupancy rate may differ by location, e.g., due to different population density and socioeconomic characteristics of the serviced areas. It is assumed that bus operators respond to the market by accounting for those location-specific differences between the four zones, e.g., by adapting fleet sizes, vehicle capacities, timetables, etc. Nevertheless, the empirical analysis seeks to account for some side factors that may influence the outcomes of interest besides the driver compensation scheme. Using bus hours as an output measure hinges on the assumption that drivers have some freedom in choosing how long they work on a given day and strict monitoring of work hours is absent. This is likely to be the case, as monitoring is one of the areas that warrant improvement according to the assessments of the Kigali bus system mentioned above.

As driver compensation schemes were not randomly assigned, general homogeneity for all bus drivers from all providers is assumed, with the compensation scheme being the primary source of variation. This simplification assumption allows causal statements. Moreover, in Kigali, the operators are free to adjust or suspend the serviced routes as they deem necessary.

Initially, Ordinary Least Squares (OLS) regressions were conducted to examine correlations between company dummies (indicating which company performs the trip) and certain serviceability indicators without adding control variables. Each company remunerates all its drivers exclusively with one compensation scheme, which hinders within-company comparisons for the effect of differing contract types. Hence, the data does not allow to distinguish between the effect of a trip being operated by a certain company and the effect of a certain compensation scheme. Accordingly, regression coefficients for the company dummies include the effect of a trip belonging to a certain operator that services a specific area in Kigali alongside the effect of a particular compensation scheme. The OLS models are constructed as follows:

$$
Y_{\text {in }}=X_{i j}+\epsilon_{i} \quad i=1, \ldots, I ; \quad j=1, \ldots J ; \quad n=1, \ldots N
$$

In this model, $Y$ denotes the dependent variable with $N$ serviceability indicators of interest [Appendix, Table 2]. $X$ contains $J$ regressors, including the company dummies, as well as the control variables. The examined dependent variables are the average revenue per kilometer, the average number of transported passengers per kilometer, the average per-passenger revenue, and the average trip speed, measured in kilometers per hour. The analysis is performed at the trip level, with each trip representing an individual driver, effectively equating "trip behavior" with "driver behavior" for analytical purposes.

Following those regressions, further OLS models were constructed to examine the effect of differing compensation schemes on the four primary outcome variables measuring driver behavior. These consist of the average per-trip occupancy rate and its standard deviation, the total time worked on a given day per driver, and the average speed per trip. Besides providing information about trip efficiency for the transport companies, measuring occupancy rates and drivers' labor supply will demonstrate the degree to which drivers are willing to alter their behavior due to compensation schemes. Importantly, incorporating average trip speeds in the analysis will allow for the investigation of road safety issues in face of performance-based contracts.

The two measures derived from the occupancy rate are intended to measure the degree of effort exhibited by drivers to gain passengers for their trips to fill their buses and accrue revenue. As noted by Johnson et al. (2015), incentive-based payment schemes may lead drivers to make shorter or longer stops and drive at different speeds to better meet the targets specified by the contract. For RFTC drivers, revenue is the prime contributor to their commission, so they have an incentive to transport as many passengers as possible, thus contributing to a higher occupancy rate on average. Once the bus is at full capacity, RFTC drivers aim to drop off passengers and substitute them with new ones, who further contribute fares and thus increase the revenue of the trip. This practice would result in a higher fluctuation of passengers on a given journey. The authors included those variables in the analysis to ascertain whether the data confirms the hypothesis.

The main concern with including measures derived from the occupancy rate is that of omitted variable bias and reverse causality. Unobserved variables, such as the socioeconomic characteristics of the neighborhoods, are highly likely to be correlated with the occupancy rate. Hence, company dummies, as well as the occupancy rate, may be correlated with said unobservables, possibly inducing omitted variable bias. While causal statements are limited, the variables were included, as correlational analysis can indicate areas for further research and point towards suggestive evidence. Regressions incorporating these dependent variables control for peak periods, per-passenger revenues, the number of bus stops along a trip, and the average distance between stops.

Total daily travel time per driver (measured in seconds) has been included in the analysis as a proxy measure for the drivers' elasticity of labor supply. As this work does not incorporate reference-dependent utility or income targeting models, it assumes that profit-maximization is always compatible with the individual utility maximization of drivers. The inclusion of income reference points in further research on incentive contracting would refine the analysis of drivers' labor supply [Schlüter et al., 2020; Camerer et al., 1997].

Average trip speed was included as an outcome variable to measure how unsafely or aggressively the buses are driven, possibly as a result of a certain compensation scheme. The regression controls for the number of stops on a route to address the possibility that route design may be inducing faster driving instead of the compensation scheme. For example, it is possible that buses are driven faster because of fewer stops. Furthermore, differential average speeds among providers may be induced by differing traffic densities throughout Kigali. While each company has the exclusive rights to service routes starting and ending in their respective zones, many of the operators' routes overlap and share portions, particularly in the center of the city. Coupled with the assumption that companies respond to the market by varying fleet sizes and compositions, and with their demonstrated willingness to adjust routes, it can be argued that a comparison of vehicle speeds is plausible in spite of the operators' differences.

Lastly, binomial and multinomial logistic regressions were conducted by effectively "reversing" the OLS models above. The logit models were constructed to cross-check the correlations exhibited in the OLS regressions and ascertain whether the indicators for driver behavior had any predictive value regarding the remuneration scheme.

The purpose of the binary logit model was to examine to which degree the variables used to measure driver behavior could predict the compensation scheme of a certain trip. A new dummy variable, salary, was created for this purpose, indicating whether a trip was operated by a company paying a fixed salary (KBS or Royal Express) or by a company offering an incentive contract.

The multinomial logit model aims to take advantage of the fact that while two types of contracts exist, there are three bus operators in Kigali to compare. The model's purpose is to predict 


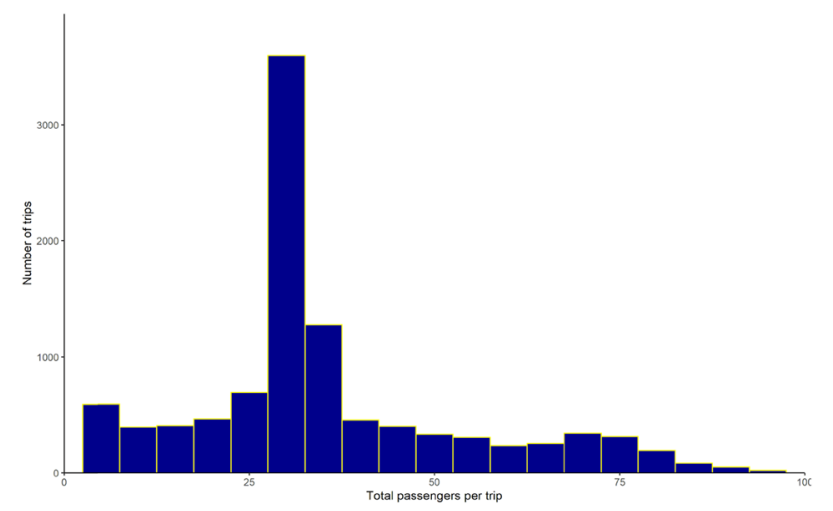

Fig. 1 Distribution of total passengers transported per trip. Source: Own representation, GoMetro Ltd.

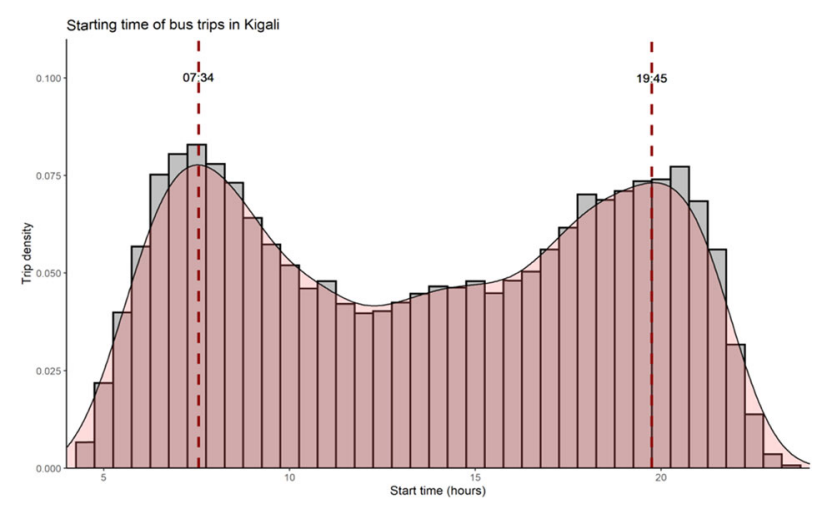

Fig. 2 Distribution of trip commencement times. Source: Own representation, GoMetro Ltd.

which company operates a given trip by examining the indicators of driver behavior as independent variables. KBS, which operates in Zone I, was chosen as the reference category. Comparing the predictive values for Royal Express with those of the reference category serves to examine to what degree differential driver behavior is due to between-company differences, as both KBS and Royal Express are the same in terms of contract type. Should the measures of driver behavior indicate similar coefficient estimates for Royal Express as for KBS, but a different one for RFTC, this would make an exclusion of company differences as a reason for variations in driver behavior more viable.

After the description of the applied empirical approach and the reasoning for respective models, the following section will present the descriptive, as well as analytical results and the details on the used data set.

\section{Results}

GoMetro Ltd. surveyed Kigali's bus network on varying dates from February to May 2019. The randomized on-board surveys collected information on stop locations for each recorded bus, the number of passengers getting on and off the buses and the respective fare, and the trip distance. The dataset consists of 11,744 individual bus trips and includes 57 routes. Further information on general bus transport in Kigali is retrieved from Allaire et al., 2019, who provide additional information on vehicle size and type, operational costs.

As shown in Fig. 1, the median bus trip in Kigali provides transportation for 30 passengers, with $75 \%$ of buses carrying at least 18 passengers during their journey. Almost 9\% of all trips start with just one passenger, possibly indicating that drivers are hoping to pick up more passengers along the road. This would

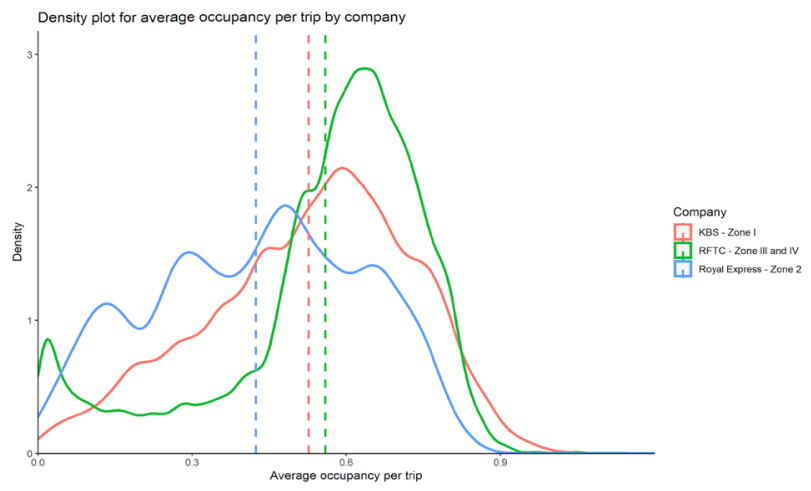

Fig. 3 Distribution of average occupancy rates by the operator. Source: Own representation, GoMetro Ltd.

especially be the case for RFTC drivers, as their remuneration partly depends on the number of passengers transported. A closer look at the data offers suggestive evidence for this hypothesis as $90 \%$ of all trips starting with one passenger are initiated by RFTC. However, only $43 \%$ of those RFTC drivers manage to acquire one more passenger. Passenger capacity in Kigali's buses ranges from 18 to 70 passengers, with close to $3 \%$ of all surveyed stops made by overloaded buses.

Kigali has a morning peak period that lasts from 07:00 to 09:00 with most journeys commencing at 07:34, and an evening peak period between 18:00 and 20:00 with most trips starting at 19:45. Figure 2 depicts starting times for bus trips in the survey.

KBS acquired the most revenue per kilometer (1012 RWF) followed by Royal Express with 922 RWF and RFTC with 724 RWF. Revenue per passenger is also the lowest for RFTC, which is surprising as RFTC drivers are supposedly incentivized by their contracts to be more productive. If we assume that bus drivers in Kigali (RFTC or otherwise) are intrinsically motivated, one could consider this result as supporting the case for the motivational crowding-out effect [Frey and Jegen, 2001]. Notwithstanding, RFTC drivers' lowest per-passenger revenue may relate to other external factors. Notably, many drivers for RFTC and KBS report lower revenue than they actually collected, with the underreporting rate at $59 \%$ for KBS drivers and at $55 \%$ for RFTC (Royal express: $38 \%$ ). Possible explanations range from fare evasion by passengers (meaning that collected revenues were smaller) to pilferage of revenue by drivers [Htun et al., 2012].

The occupancy rate as a metric for bus trip efficiency is henceforth defined as the number of passengers present in a bus at a given point of the journey relative to the total capacity of the vehicle. The dataset does not specify the type and capacity of each bus. In order to enable the unambiguous identification of vehicle capacity for every trip, only those routes that are serviced by a single bus model are included in the analyses. Figure 3 describes the average per-trip occupancies grouped by service providers. RFTC exhibits the highest average occupancy rate per trip, with $56 \%$ of vehicle capacity being utilized for the average journey (KBS: $52.8 \%$, Royal Express: 42.4\%). When measured by this indicator, RFTC is the most efficient among all providers. The high average occupancy rate for RFTC is not surprising, as their buses have the lowest capacities (max. 29 passengers) compared to the vehicles of their competitors (max. 70 passengers). Moreover, an average RFTC trip carries 27.3 passengers while the other providers transport an average of 38 to 46 . In order to account for the variance in vehicle capacities, a series of Wilcox tests were conducted comparing various indicators such as revenue per passenger, revenue per kilometer, the average distance between bus stops, etc. The means of all indicators in the shrunken dataset were significantly different from the original at the $5 \%$ 
significance level. The assumption that the existence of buses with differing capacities on a route is not correlated with outcome variables such as the occupancy rate could not be rejected either based on our tests or on a review of the empirical literature.

If we assume that higher-income increases individual utility and drivers pursue utility-maximizing behavior, it would be in the interest of RFTC drivers to obtain as many passengers as possible along the journey to increase revenue. However, this assumption is dependent on whether a driver has achieved his/her income reference point if the employee is characterized by referencedependent utility [Schlüter et al., 2020]. The analysis however assumes that profit-maximization is the prime engine for utility maximization, which may manifest in stopping at non-designated places and waiting for passengers for long periods of time [Htun et al., 2012]. On average, this would induce a higher passenger fluctuation, which is hereafter defined as the standard deviation of the occupancy rate for a given trip [see Appendix, Figure 5]. Supporting the hypothesis above, RFTC exhibits the highest average fluctuation rate among all companies at 0.316 standard deviations. KBS and Royal Express follow with 0.250 and 0.237 standard deviations, respectively.

While bus transport in Kigali does have a timetable, it is known for a general lack of service reliability and punctuality [City of Kigali, 2019]. This suggests that drivers could be exercising a certain degree of freedom to conduct or alter trips at their own discretion. While increased labor supply may contribute to profit maximization, more work may not always be compatible with utility maximization due to the possibility of drivers having income reference points [Schlüter et al., 2020]. The latter can be studied through the examination of daily work hours for drivers [see Appendix, Fig. 6].

As drivers have direct control over the speed of the vehicle, average speeds per trip by the operator are used as a metric to measure driver behavior [see Appendix, Fig. 7]. In this paper, speed serves as a proxy for safe driving. All else equal, it is assumed that the faster driving indicates unsafe behavior on part of the driver [Hauer, 2009]. RFTC trips exhibit the highest average velocity at 21.6 kilometers per hour followed by KBS (17.3) and Royal Express (15.5).

OLS regressions are applied to the four primary indicators of driver behavior [see Appendix, Table 3 and Table 4]. A simple regression on the company dummies revealed that both KBS and Royal Express exhibit lower average occupancy rates than RFTC. However, this simple model accounts for a mere 2 percent of the variation in mean occupancy rates. A second model controlled for peak periods, i.e., whether trips took place in the rush hour, and for average vehicle speeds. This specification strengthened the correlations found above, with KBS now having an occupancy rate that is 6.4 percentage points lower than that of RFTC (which rose from 56 to 67.6 percent), with the coefficient for Royal Express standing at 16.9 percentage points. Moreover, R-squared increased to 0.079 . These results serve to illustrate that RFTC is seemingly better at fully utilizing its vehicle capacity, and suggests that its operational efficiency is relatively higher. While this result is not necessarily based on the differential payment scheme, if the assumption regarding the operators' rationality, access to information, and market responsiveness hold, these correlations can be interpreted as at least suggestive of the hypothesis above.

The regression on average trip speeds (measured in kilometers per hour) revealed that both Royal Express and KBS drive consistently slower than RFTC, even when variables such as stop density and per-passenger revenue are controlled for. The estimates for KBS and Royal Express are notably similar, and they are robust to bus stop density. This suggests that an incentive scheme is indeed associated with faster driving, but definitive causal statements cannot be made, partly due to possible endogeneity but also due to the imperfect nature of the proxy variable. Further detailed results from the regression analysis can be found in the appendix.

Estimating the binomial logit model showed that three of the four variables measuring driver behavior have predictive value when it comes to the compensation scheme of a specific employee [see Appendix, Table 5]. All coefficient estimates are statistically significant except daily per-bus travel time. The results demonstrate that a higher average occupancy rate makes it more likely that a given trip will be classified as belonging to a company paying a fixed salary, which directly contradicts the previous results from the OLS regression: While the previous regression showed that on average a trip belonging to KBS or Royal Express was associated with a decreased occupancy rate, the logit model suggests the contrary. The coefficient estimate of the proxy variable for labor supply is neither statistically nor economically significant, as it is close to zero. As for passenger fluctuation, the result seemingly verifies the previous regression: An increase of the standard deviation of the occupancy rate for a given trip by one unit decreases the logit by approximately 12.08 , i.e., more passenger fluctuation makes it less likely that a given trip will be classified as one belonging to KBS or Royal Express. Estimating the predictive value of the average trip speed offered similar results: An increase of this indicator by one unit decreases the logit by about 0.25 . This result goes in line with the OLS regression, i.e., higher speeds make it less likely that a given trip is performed by a company paying a fixed wage. In conclusion, the binomial logistic regression did not verify all results of the previous estimation, with one variable contradicting the latter and one lacking statistical significance.

The multinomial logit model attempted to use the existence of two firms paying a fixed wage to its advantage [Table 1]. The average per-trip occupancy rate has a similar predictive value for both RFTC and Royal Express: Higher occupancy rates make it less likely that a given trip is classified as one belonging to RFTC or Royal Express, and more likely that it is operated by KBS. Moreover, the value of the coefficient estimate for RFTC is -1.97 , which is smaller in magnitude than Royal Express' - 5.2. As the estimate for RFTC lies effectively "between" those of KBS and Royal Express, it cannot be concluded that the average occupancy rate unambiguously predicts the remuneration scheme of a particular driver on a given trip.

Following the results from the binomial logit model, the magnitude of the coefficient estimate for daily per-bus travel time remained infinitesimal for both RFTC and Royal Express in spite of a $p$-value below 0.01 , i.e., a change in daily labor supply has an effect so small that it is economically insignificant.

The standard deviation of the occupancy rate exhibited positive predictive values for both RFTC and Royal Express, with both estimates being statistically significant. While more passenger fluctuation makes it more likely that a given trip will be classified as one operated by Royal Express or RFTC, the effect for RFTC is stronger. Hence, it can be argued that the positive coefficient estimate for Royal Express captures the differences between this company and KBS. Assuming that differences (aside from contract type) between KBS and Royal Express are comparable to differences between Royal Express and RFTC, the pay scheme would be the primary difference between the latter two firms. If this assumption holds, the larger coefficient estimate for RFTC can be interpreted as indicative of the effect of performance-based pay, thus confirming the previous results from the OLS regression.

Lastly, a higher average trip speed increases the probability that a given trip will be classified as one operated by RFTC. As the magnitude of the estimate for RFTC is greater than that of Royal Express, a conclusion similar to the one regarding passenger 


\begin{tabular}{|c|c|}
\hline & $\begin{array}{l}\text { Multinomial logit model } \\
\text { predicting companies }\end{array}$ \\
\hline RFTC-Zone III and IV: (Intercept) & $-5.375^{\star \star \star}(0.000)$ \\
\hline RFTC-Zone III and IV: occupancy rate & $-1.966^{\star \star \star}(0.000)$ \\
\hline $\begin{array}{l}\text { RFTC-Zone III and IV: total travel time } \\
\text { per day }\end{array}$ & $-0.000^{\star \star \star}(0.000)$ \\
\hline RFTC-Zone III and IV: passenger fluctuation & $13.597^{\star \star \star}(0.000)$ \\
\hline RFTC-Zone III and IV: speed & $0.245^{\star \star \star}(0.001)$ \\
\hline Royal Express-Zone 2: (intercept) & $0.249^{\star \star \star}(0.000)$ \\
\hline Royal Express-Zone 2: occupancy rate & $-5.198^{\star \star \star}(0.000)$ \\
\hline $\begin{array}{l}\text { Royal Express-Zone 2: total travel time } \\
\text { per day }\end{array}$ & $-0.000^{\star \star \star}(0.000)$ \\
\hline Royal Express-Zone 2: passenger fluctuation & $7.096^{\star \star \star}(0.000)$ \\
\hline Royal Express-Zone 2: speed & $-0.036^{\star \star \star}(0.002)$ \\
\hline AIC & 67.341 .548 \\
\hline $\mathrm{BIC}$ & 67.432 .562 \\
\hline Log-Likelihood & -33.660 .774 \\
\hline Deviance & 67.321 .548 \\
\hline Num. obs. & 66266 \\
\hline K & 3 \\
\hline
\end{tabular}

fluctuation can be made for the same reasons. If the named assumption holds, the positive coefficient estimate for RFTC can be interpreted as suggestive of the positive association between faster driving and performance-based compensation.

\section{Discussion}

The results of the empirical investigation indicate that incentivebased remuneration schemes are associated with drivers adapting their behavior for higher passenger fluctuation. Moreover, performance pay also involves faster driving speeds in the case of Kigali. These findings are discussed in the following and some caveats are briefly mentioned.

Among the four variables used to measure driver behavior, high passenger fluctuation and speeds are strongly associated with performance-based pay, with the logit models "verifying" the preceding OLS regressions. Even after controlling for stop density, RFTC drivers exhibited a higher standard deviation of the occupancy rate on their trips. It is possible that this is due to drivers stopping at non-designated areas to pick up or let off passengers so they can increase their revenue [Htun et al., 2012]. Assuming that this constitutes utility-maximizing behavior on part of the drivers, this would serve to validate the principal-agent framework. Alternatively, in the absence of strict real-time driver monitoring, drivers can also deviate from their assigned routes to maximize revenue per kilometer [Rusco and Walls, 2001]. Both options introduce more sources of passenger fluctuation in the form of increased stops, which would explain the correlation with incentive contracts.

As some RFTC routes are located outside central Kigali, it is possible that higher vehicle speeds are due to lower traffic congestion or lower stop density in Zones 3 and 4 . However, as RFTC drivers are paid based on their performance, their utilitymaximizing behavior incentivizes them to additionally stop at unauthorized areas to pick up passengers. This ramps up the "true" bus stop density, i.e., buses stop more frequently than documented in the data. RFTC buses tend to be faster than their counterparts in spite of the negative correlation between stop density and average vehicle speeds, which lends grounds to the interpretation of the results as indicative of the payment scheme's influence.

The findings of this work are largely consistent with the conclusions of Rusco and Walls (2001) whilst examining minibus competition in Hong Kong. Compared to drivers that are compensated with a fixed wage, RFTC buses tend to drive faster, thus contributing to lower travel times. Moreover, the correlations demonstrated by the OLS regressions on passenger fluctuation suggest that drivers may "reduce the quality of their output" to maximize revenue, e.g., by taking detours or stopping at undesignated areas, which lowers service quality from the passengers' perspective. This can be interpreted as grounds for the generalizability of the results of Paarsch and Shearer (2001) and also corroborates the findings of Behrens et al. (2017). However, further research is needed to enable the external validation of these papers' findings in Kigali.

Notwithstanding, the analysis has some limitations, e.g., in ideal research setting there would be stratified randomization within routes and not only between routes. In Santiago, Johnson et al. (2015) exploited the natural coexistence of varying compensation schemes within routes to address this concern, ensuring that drivers differ only along with the payment scheme by design. The lack of random assignment of the compensation schemes aggravates endogeneity concerns and hinders definitive causal statements. Hence, it is important to interpret the results of this work with caution. Moreover, the imperfect measurement of driver behavior is among the main caveats of this paper. While actions on part of the driver are bound to have an impact on occupancy rates, labor supply, and vehicle speeds, all variables are also influenced by factors external to driver behavior. Furthermore, individual characteristics of the drivers may also bear relevance, particularly when it comes to speed selection [Jørgensen and Polak, 1993]. If drivers are heterogeneous, the assumptions above will not suffice to rule out contamination, as companies' market responsiveness cannot influence unobservable factors such as drivers' attitudes and perceptions. Here, the interpretation relies on the assumption that drivers across companies are sufficiently homogenous when it comes to these variables. Furthermore, information regarding the monitoring of the agents by the principals is imperfect. Similarly, "driver behavior" was equated with "bus behavior" for analytical purposes. Data collection pertaining to individual driver characteristics is still warranted. Variables such as age, income, marital status, and attitudes towards travel time savings and penalties should be included in the data collection, allowing for the construction of a more expanded model, which would serve to better isolate the effects of the compensation scheme on driver behavior.

When constructing multidimensional measures of driver behavior, it is important to take the interests of various stakeholders in public transport into account. For example, occupancy rates and passenger fluctuation are relevant indicators for transport companies as better utilization of vehicle capacity would lead to fewer costs and increased efficiency. Assuming that passengers substitute private cars with buses, high occupancy rates in public transport could also be desirable from an environmental perspective, as it would mean reduced traffic congestion and air pollution. However, as suggested by this paper and by the Santiago study, a performance-based compensation scheme could be harmful to passenger comfort and safety [Johnson et al., 2015]. Hence, indicators measuring the safety of driving practices and the nature of drivers' interactions with passengers should also be included in such an analysis.

Objective, quantitative measures of driver behavior that affect passenger satisfaction can be difficult to obtain. In this case, qualitative data collection is warranted, i.e., conducting interviews with relevant stakeholders and collecting subjective assessments of 
their satisfaction with the drivers' behavior. Inspiration for taking the institutional background and political economy factors into account can be drawn from further studies in the Sub-Saharan African context [Boateng, 2020, Boateng, 2021]. Data from administrative registries regarding traffic accidents involving buses can also be used to supplement the analysis. Furthermore, drivers themselves are important stakeholders in public transport.

When designing incentive schemes, taking the drivers' interests into account can be mutually beneficial for the company and for the driver, as this can lead to more revenue for the company due to increased driver satisfaction. A study from Lagos highlights the importance of this issue, where drivers' safety, health, and job insecurity continue to have an adverse effect on road safety [Agbiboa, 2016]. In Santiago, where incentive schemes have seen an increased proliferation in bus transport, drivers reported poor treatment by passengers as the prime source for working stress [Tiznado et al., 2014]. Poor working conditions and increased stress levels can have an adverse effect on drivers' behavior, further introducing sources of variation beyond the compensation scheme [Duffy and McGoldrick, 1990, Evans and Carrère, 1991, Kompier and Di Martino, 1995]. In some cases in Santiago, incentive schemes were tied to consumer satisfaction, so the passenger-driver relationship can bear direct relevance for this research question in such settings. From a societal perspective, performance-based contracts that primarily incentivize drivers to increase revenue (such as RFTC contracts) may also lead to a decreased willingness to transport elderly and disabled passengers [Htun et al., 2012]. Assessing the degree to which access to public transport for these groups is inhibited by driver behavior is difficult, especially in a developing-country setting. Nevertheless, this question can be included in future assessments, as it is a relevant indicator of driver behavior from a societal perspective.

Looking forward and as an indicator for the relevance of this paper, the Government of the City of Kigali continues to show considerable interest in upgrading and developing bus transport. The government is currently implementing a seven-year program (from 2017 to 2024) to improve public transport and is planning to introduce Bus Rapid Transit (BRT) in the city [Nkurunziza, 2019]. Moreover, RFTC has taken the first steps to increase the accessibility of public transport for disabled passengers by importing inclusive public buses, with plans to unveil more in the future [Barungi, 2019]. Most importantly, "Public Transport Generation 2" is being started in 2020, with the Rwanda Utilities Regulatory Authority (RURA) setting new requirements for transport providers. Moreover, intelligent service monitoring systems are set to be implemented to "track vehicle activity and performance". RURA also envisages "improve route planning and service contracts" [Bizimungu, 2019, Kuteesa, 2019a].

For bus drivers, these dynamics mean that their performance can be monitored more closely by their employers. Furthermore, they will have little possibility to alter routes or stop at undesignated areas due to stricter monitoring and regulations. In fact, the Head of the Transport Department at RURA stated that "this time they will be using ICT to be able to control the drivers" [Kuteesa, 2019b]. Recalling the theoretical framework of this paper, these trends suggest that there will be less capacity for hidden action on part of the drivers, so this aspect of the principal-agent problem will bear less relevance once Public Transport Generation 2 is fully implemented. However, the availability of more detailed information for the principal can lead to a more complex compensation scheme that effectively incorporates and monitors more dimensions than revenue alone.

In light of these expectations for the future of Kigali's bus network, the results of this paper have some important policy implications for companies and regulators alike. Companies must take into account that incentive contracts, which are primarily based on profitability measures, may induce faster and more aggressive driving practices. Performance-based pay may encourage competition among drivers, which may be detrimental to passenger comfort and safety if measures that account for the latter are not included in remuneration schemes. Moreover, operators must recognize that by altering their behavior to acquire more passengers or increase fluctuation (as suggested by the OLS regression), drivers that had an incentive contract were contributing to corporate revenue and financial success. The introduction of stricter monitoring and regulations by RURA in 2020 will hinder such practices in the future, meaning that companies will have to adapt to avoid potential decreases in revenue. The authorities must anticipate the possibility that drivers will alter their behavior in other unobservable ways to maximize their commission in spite of the upcoming reforms and ensure passenger safety. As more detailed data will become available regarding driving practices, the proper analysis will ensure that the authorities can respond accordingly if drivers or their employers deviate from safety regulations. In the long run, this can lead to the development of multidimensional compensation schemes that will ensure that the interests of relevant stakeholders are taken into account when designing contracts for public transport services.

\section{Conclusion}

This paper examined the influence of incentive-based compensation schemes (or the lack thereof) on multiple indicators of bus drivers' behavior in Kigali, Rwanda. A preliminary descriptive analysis established that buses belonging to RFTC (which offers incentive contracts) exhibited higher vehicle occupancy and passenger fluctuation than their counterparts with fixed wages. Subsequent OLS models that controlled for several observables confirmed the correlations. As for daily work hours, OLS regressions found that RFTC drivers, on average, work longer hours than others, with the results being robust to average travel speeds. Accordingly, the findings suggest that the deployment of a principal-agent framework is justified as incentivized agents altered their behavior to maximize their utility. Further analysis also confirmed that agents with an incentive contract drive faster on average, with the result being robust to bus stop density.

Logistic regressions that were constructed to cross-check these results verified that high passenger fluctuation and increased speed have positive predictive power with regards to the employer (and hence, the compensation scheme) of a given driver, while a contradictory result was obtained for the occupancy rate. Taking this into account, it can be concluded that bus drivers, who are compensated based on their performance, are more willing to alter their behavior to achieve high passenger fluctuation. Moreover, drivers with an incentive contract are also more likely to drive faster, which may lead to an increased accident rate. The latter result is in line with the findings of Johnson et al. (2015). While other modes of transport such as motorcycles are also prone to accidents, the research focus of this paper is limited to buses due to data constraints. The investigation of road safety issues for other popular modes of transport is an interesting subject for further research.

The main limitation of this paper is the lack of definitive causal results lest unverifiable assumptions are made. This is mainly due to the lack of a reliable comparison group for those with incentive contracts, as compensation schemes were not randomly assigned and are endogenous. The effect of the remuneration scheme could only be compared across different zones and companies, inhibiting the establishment of causal relationships. However, OLS models and subsequent logistic regressions provide suggestive evidence of an association of high passenger fluctuation and speeds with incentive contracts. 
More evidence regarding this issue could be collected if companies and policymakers utilize digital data collection. Furthermore, the construction of a multidimensional indicator of driver behavior that will measure further aspects in detail is warranted, e.g., environmentally friendly driving, safe driving, etc. Further research with more detailed data and an experimental design is necessary to ascertain the causal impact of various compensation schemes on driver behavior. This area of research remains relevant in spite of the advent of better monitoring, tighter regulations, and dedicated bus lanes. As drivers continue to retain ultimate control over the vehicle, understanding the factors that influence their behavior is paramount. A precise understanding of drivers' motivation could then lead to more adequate incentivization of positive behavior rather than the introduction of punitive measures. This can permit more attractive public bus transport and, in return, attract more passengers in the future.

\section{Data availability}

The data sets cannot be made public. The data that has been used is confidential. This is because of data protection concerns, as very personal data are part of the travel data sets.

Received: 28 November 2020; Accepted: 6 September 2021; Published online: 08 October 2021

\section{References}

Agbiboa DE (2016) 'No Condition IS Permanent': informal transport workers and labour precarity in Africa's largest city. Int $J$ Urban Region Res 40(5):936-957

Ali R, Barra A, Berg C, Damania R, Nash J, Russ J (2015) Highways to Success or Byways to Waste: Estimating the Economic Benefits of Roads in Africa. The World Bank. Retrieved from https://elibrary.worldbank.org/doi/pdf/10.1596/ 978-1-4648-0654-4

Aljoufie M, Zuidgeest M, Brussel M, van Maarseveen M (2013) Spatial-temporal analysis of urban growth and transportation in Jeddah City, Saudi Arabia. Cities 31:57-68. https://doi.org/10.1016/j.cities.2012.04.008

Allaire J, Neta M, McLachlan N, Molomo M, Granjard M, Ackerman P, Coetzee J, Zhuwak N, Nteziyaremye P, Mzengereza I, Reddy P, Hegazy M (2019) Business Model for Public Transport Services in the City of Kigali [Unpublished]. Transitec

Baffoe G, Malonza J, Manirakiza V, Mugabe L (2020) Understanding the concept of neighbourhood in Kigali City, Rwanda. Sustainability 12:1555

Barungi, B. (2019). New inclusive public buses raise optimism among disabled people. The New Times. https://www.newtimes.co.rw/news/new-inclusivepublic-buses-raise-optimism-among-disabled-people

Behrens R, McCormick D, Orero R, Ommeh M (2017) Improving paratransit service: lessons from inter-city matatu cooperatives in Kenya. Transport Policy 53:79-88

Bizimungu, J. (2019). RURA introduces new reforms in Kigali public transport system. The New Times. https://www.newtimes.co.rw/news/rura-introducesnew-reforms-kigali-public-transport-system

Boateng FG (2020) "Indiscipline" in context: a political-economic grounding for dangerous driving behaviors among Tro-Tro drivers in Ghana. Humanit Soc Sci Commun 7(1):1-5. https://doi.org/10.1057/s41599-020-0502-8

Boateng FG (2021) Why Africa cannot prosecute (or even educate) its way out of road accidents: insights from Ghana. Humanit SocSci Commun 8(1):1-11. https://doi.org/10.1057/s41599-020-00695-5

Brekke KR, Holmås TH, Monstad K, Straume OR (2020) How does the type of remuneration affect physician behavior? Am J Health Econ 6:104-138. https://doi.org/10.1086/706624

Bryceson DF, Mbara TC, Maunder D (2003) Livelihoods, daily mobility and poverty in sub-Saharan Africa. Transport Rev 23:177-196. https://doi.org/ $10.1080 / 01441640309891$

Burks S, Carpenter J, Goette L (2009) Performance pay and worker cooperation: evidence from an artefactual field experiment. J Econ Behav Organizat 70:458-469. https://doi.org/10.1016/j.jebo.2008.02.012

Camerer C, Babcock L, Loewenstein G, Thaler R (1997) Labor supply of New York City cabdrivers: one day at a time. Quart J Econ 112:407-441. https://doi.org/ $10.1162 / 003355397555244$
City of Kigali (2019) Interim Transport Master Plan Report. https:// masterplan2019.kigalicity.gov.rw/portal/sharing/rest/content/items/ 263be3f4159248218a53cee30f47c4b8/data

Colenbrander S, Sudmant A, Chilundika N, Gouldson A (2019) The scope for lowcarbon development in Kigali, Rwanda: an economic appraisal. Sustain Dev 27(3):349-365. https://doi.org/10.1002/sd.1906

Conlon EJ, Parks JM (1990) Effects of monitoring and tradition on compensation arrangements: an experiment with principal-agent dyads. Acad Manag J 33:603-622. https://doi.org/10.5465/256583

Daido K (2007) A behavioral economic approach to performance-based wage systems. Japan Labor Rev 4:37

Dickinson D, Villeval MC (2008) Does monitoring decrease work effort?: the complementarity between agency and crowding-out theories. Games Econ Behav 63(1):56-76. https://doi.org/10.1016/.geb.2007.08.004

Dohmen T, Falk A (2011) Performance pay and multidimensional sorting: productivity, preferences, and gender. Am Econ Rev 101:556-90. https://doi.org/ 10.1257/aer.101.2.556

Dotse J, Nicolson R, Rowe R (2019) Behavioral influences on driver crash risks in Ghana: a qualitative study of commercial passenger drivers. Traffic Injury Prevent 20(2):134-139. https://doi.org/10.1080/15389588.2018.1556792

Duffy CA, McGoldrick AE (1990) Stress and the bus driver in the UK transport industry. Work Stress 4:17-27. https://doi.org/10.1080/02678379008256961

Eriksson T, Villeval MC (2008) Performance-pay, sorting and social motivation. J Econ Behav Organizat 68:412-421. https://doi.org/10.1016/j.jebo.2007.10.003

Evans GW, Carrère S (1991) Traffic congestion, perceived control, and psychophysiological stress among urban bus drivers. J Appl Psychol 76:658

Fehr E, Goette L (2007) Do workers work more if wages are high? Evidence from a randomized field experiment. Am Econ Rev 97:298-317. https://doi.org/ 10.1257/aer.97.1.298

Frey BS (1993) Does monitoring increase work effort? The rivalry with trust and loyalty. Econ Inquiry 31:663-670. https://doi.org/10.1111/j.1465-7295.1993.tb00897.x

Frey BS, Oberholzer-Gee F (1997) The cost of price incentives: an empirical analysis of motivation crowding- Out. Am Econ Rev 87:746-755

Frey BS, Jegen R (2001) Motivation crowding theory. J Econ Surveys 15:589-611. https://doi.org/10.1111/1467-6419.00150

Ghatak M, Pandey P (2000) Contract choice in agriculture with joint moral hazard in effort and risk. J Dev Econ 63:303-326. https://doi.org/10.1016/S03043878(00)00116-4

Gneezy U, Rustichini A (2000) Pay enough or don't pay at all. Quart J Econ 115:791-810. https://doi.org/10.1162/003355300554917

Gosden T, Forland F, Kristiansen I, Sutton M, Leese B, Giuffrida A, Pedersen L (2000) Capitation, salary, fee-for-service and mixed systems of payment: effects on the behaviour of primary care physicians. Cochrane Database Syst Rev 3 (CD002215). https://doi.org/10.1002/14651858.CD002215

Gwilliam K (2003) Urban transport in developing countries. Transport Rev 23:197-216. https://doi.org/10.1080/01441640309893

Hart OD, Holmström B (1987) The theory of contracts. The theory of contracts. Advances in economic theory: Fifth world congress (Vol. 1). Cambridge University Press, Cambridge

Hauer E (2009) Speed and Safety. Transport Res Record 2103(1):10-17. https:// doi.org/10.3141/2103-02

Htun PT, Nakamura F, Okamura T, Wang R (2012) Influences of bus drivers' salary system on their behaviors. Asian transport. Studies 2:209-220. https:// doi.org/10.11175/eastsats.2.209

Iles R (2005) Public transport in developing countries. public transport in developing countries. Emerald Group Publishing Limited

ITF [International Transport Forum] (2017) ITF Transport Outlook 2017, OECD Publishing, Paris, https://doi.org/10.1787/9789282108000-en

Jensen MC, Meckling WH (1976) Theory of the firm: managerial behavior, agency costs and ownership structure. J Financ Econ 3:305-360. https://doi.org/ 10.1016/0304-405X(76)90026-X

Johnson DG (1950) Resource allocation under share contracts. J Polit Econ 58:111-123. https://doi.org/10.1086/256919

Johnson RM, Reiley DH, Muñoz JC (2015) "The war for the fare": how driver compensation affects bus system performance. Econ Inquiry 53:1401-1419. https://doi.org/10.1111/ecin.12188

Jones MD (2013) Teacher behavior under performance pay incentives. Econ Educ Rev 37:148-164. https://doi.org/10.1016/j.econedurev.2013.09.005

Jørgensen F, Polak J (1993) The effect of personal characteristics on drivers' speed selection: an economic approach. J Transport Econ Policy 27:237-252

Kahneman D, Tversky A (1979) Prospect theory: an analysis of decisions under risk. Econometrica 47:263-291

Kompier MA, Di Martino V (1995) Review of bus drivers' occupational stress and stress prevention. Stress Med 11:253-262. https://doi.org/10.1002/ smi.2460110141

Kuteesa H (2019a) Inside the next generation of Kigali's public transport. The New Times. https://www.newtimes.co.rw/news/inside-next-generationkigalis-public-transport 
Kuteesa H (2019b) RURA raises the bar for public transport operators. The New Times. https://www.newtimes.co.rw/news/rura-raises-bar-public-transport-operators

Kutzbach MJ (2009) Motorization in developing countries: causes, consequences, and effectiveness of policy options. J Urban Econ 65:154-166. https://doi.org/ 10.1016/j.jue.2008.10.002

Kwon I (2014) Motivation, discretion, and corruption. J Public Administration Res Theory 24:765-794. https://doi.org/10.1093/jopart/mus062

Laffont J-J, Martimort D (2009) The theory of incentives: the principal-agent model. Princeton University Press

Lazear EP (2000) Performance pay and productivity. Am Econ Rev 90:1346-1361. https://doi.org/10.1257/aer.90.5.1346

Lazear EP (1986) Incentive contracts. NBER Working Paper Series. https:// www.nber.org/papers/w1917.pdf

Maveneka L, Ruramira Z (2013) Final End of the Programme Evaluation of the Support to Access to justice for all, the Foundation for Good Governance and Poverty Reduction, Rwanda (2008-2013). United Nations Development Programme. https://erc.undp.org/evaluation/documents/download/7656

Nguyen Q, Leung P (2009) Choice of remuneration regime in fisheries: the case of Hawaii's longline fisheries. J Agric Res Econ 34:498-517

NISR [National Institute of Statistics of Rwanda] (2012) Fourth Population and Housing Census - 2012. Retrieved from https://www.statistics.gov.rw/ datasource $/ 42$

Nkurunziza M (2019) Kigali city bus stops to go hi-tech. The New Times. https:// www.newtimes.co.rw/news/kigali-city-bus-stops-go-hi-tech

Obeng-Odoom F (2010) Drive left, look right: the political economy of urban transport in Ghana. Int J Urban Sustain Dev 1(1-2):33-48

Olynk NJ, Wolf CA (2010) Aligning incentives for contract dairy Heifer growth. J Agric Res Econ 35:489-502

Paarsch HJ, Shearer B (2001) Piece rates, fixed wages, and incentive effects: statistical evidence from payroll records. Int Econ Rev 41:59-92. https://doi.org/ $10.1111 / 1468-2354.00055$

Palmrose Z-V (1989) The relation of audit contract type to audit fees and hours. Account Rev 64:488-499

Pham TT, Flaaten O, Nguyen TK (2013) Remuneration systems and economic performance: theory and Vietnamese small-scale purse seine fisheries. Marine Res Econ 28:19-41. https://doi.org/10.5950/0738-1360-28.1.19

Poblete J, Spulber D (2012) The form of incentive contracts: agency with moral hazard, risk neutrality, and limited liability. RAND J Econ 43:215-234. https://doi.org/10.1111/j.1756-2171.2012.00163.x

Prendergast C (1999) The provision of incentives in firms. J Econ Literat 37:7-63. https://doi.org/10.1257/jel.37.1.7

Pucher J, Park HY, Kim MH, Song JM (2005) Public transport in Seoul: meeting the burgeoning travel demands of a megacity. Public Transport Int 54:54-61

REMA [Rwanda Environment Management Authority] (2013) State of Environment and Outlook Report. Technical Report. Kigali. http://wedocs.unep.org/ handle/20.500.11822/9069

Rizzo M (2011) 'Life is War': Informal Transport Workers and Neoliberalism in Tanzania 1998- 2009. Dev Change 42(5):1179-1206

Rusco FW, Walls WD (2001) Red bus, green bus: Market organization, driver incentives, safety, and sorting. Res Transport Econ 6:121-142. https://doi.org/ 10.1016/S0739-8859(01)80009-3

Rusco FW, Walls WD (2004) Transit System Performance and Industrial Economics: Learning from Hong Kong Maxicabs and Philippine Jeepneys. In Applications of Advanced Technologies in Transportation Engineering. American Society of Civil Engineers. pp. 187-192. https://doi.org/10.1061/ 40730(144)35

Santoso DS, Yajima M, Sakamoto K, Kubota H (2012) Opportunities and strategies for increasing bus ridership in rural Japan: a case study of Hidaka City. Transport Policy 24:320-329. https://doi.org/10.1016/j.tranpol.2012.09.005

Schalekamp H, Behrens R (2010) Engaging paratransit on public transport reform initiatives in South Africa: a critique of policy and an investigation of appropriate engagement approaches. Res Transport Econ 29(1):371-378

Schlüter J, Frewer M, Sörensen L, Coetzee J (2020) A stochastic prediction of minibus taxi driver behaviour in South Africa. Humanit Soc Sci Commun 7:1-12. https://doi.org/10.1057/s41599-020-0508-2

Sietchiping R, Permezel MJ, Ngomsi C (2012) Transport and mobility in subSaharan African cities: an overview of practices, lessons and options for improvements. Cities 29:183-189. https://doi.org/10.1016/j.cities.2011.11.005

Simon HA (1955) A behavioral model of rational choice. Quart J Econ 69:99-118. https://doi.org/10.2307/1884852
Stiglitz JE (1974) Incentives and risk sharing in sharecropping. Rev Econ Stud 41:219-255

Strausz R (1997) Delegation of monitoring in a principal-agent relationship. Rev Econ Stud 64:337-357. https://doi.org/10.2307/2971717

Stucki M (2015) Policies for sustainable accessibility and mobility in urban areas of Africa. Working Paper. Washington, DC: World Bank Group. Retrieved from http://hdl.handle.net/10986/24089

Tembe A, Nakamura F, Tanaka S, Ariyoshi R, Miura S (2019) The demand for public buses in sub-Saharan African cities: Case studies from Maputo and Nairobi. IATSS Res 43:122-130. https://doi.org/10.1016/j.iatssr.2018.10.003

The World Bank. (2014). Transport: Sector Results Profile. Retrieved from https:// www.worldbank.org/en/results/2013/04/14/transport-results-profile

Tirole J (1986) Hierarchies and bureaucracies: on the role of collusion in organizations. J Law Econ Organizat 2:181-214

Titmuss R (1998) The gift of blood. Society 35:88-97

Tiznado I, Galilea P, Delgado F, Niehaus M (2014) Incentive schemes for bus drivers: the case of the public transit system in Santiago, Chile. Res Transport Econ 48:77-83. https://doi.org/10.1016/j.retrec.2014.09.034

Twarabamenye E, Mukashema A (2012) Long-run trend of cities' informal housing: a solution for the majority of Kigali Urban dwellers and a challenge to urban development in Rwanda. J Environ Manag 3:35-56

Wakabayashi T (2019) Fixed salary or incentive contract? The effect of stickiness of compensation contracts. Asia-Pacific. J Account Econ 0:1-12. https://doi.org/ $10.1080 / 16081625.2019 .1673191$

Weibel A, Rost K, Osterloh M (2009) Pay for performance in the public sectorbenefits and (hidden) costs. J Public Administration Res Theory 20:387-412. https://doi.org/10.1093/jopart/mup009

Weitzman ML (1980) Efficient incentive contracts. Quart J Econ 94:719-730. https://doi.org/10.2307/188566

\section{Acknowledgements}

The authors would like to thank L.V. from the University of Göttingen, who does not wish to be named, for his cooperation in this publication. L.V. has made essential parts of the publication, but for personal reasons he does not want to be mentioned with his full name.

\section{Funding}

Open Access funding enabled and organized by Projekt DEAL.

\section{Competing interests}

The authors declare no competing interests.

\section{Additional information}

Supplementary information The online version contains supplementary material available at https://doi.org/10.1057/s41599-021-00896-6.

Correspondence and requests for materials should be addressed to Jan Schlüter.

Reprints and permission information is available at http://www.nature.com/reprints

Publisher's note Springer Nature remains neutral with regard to jurisdictional claims in published maps and institutional affiliations.

Open Access This article is licensed under a Creative Commons Attribution 4.0 International License, which permits use, sharing, adaptation, distribution and reproduction in any medium or format, as long as you give appropriate credit to the original author(s) and the source, provide a link to the Creative Commons license, and indicate if changes were made. The images or other third party material in this article are included in the article's Creative Commons license, unless indicated otherwise in a credit line to the material. If material is not included in the article's Creative Commons license and your intended use is not permitted by statutory regulation or exceeds the permitted use, you will need to obtain permission directly from the copyright holder. To view a copy of this license, visit http://creativecommons.org/ licenses/by/4.0/

(C) The Author(s) 2021 